\title{
SOBRE LA CERTIDUMBRE
}

Eva Parra Iñesta*

El siguiente ensayo hace un breve recorrido a través de algunos parágrafos escogidos de Sobre la certeza centrándose en el diálogo que entabla Wittgenstein con G. E. Moore acerca del escepticismo.

\section{Palabras claves}

Certeza, Wittgenstein, escepticismo, proposiciones gramaticales, proposiciones empíricas

The present Essay goes through some paragraphs picked out of Wittgenstein's On Certainty, focousing in the dialoge that the author starts with G. E. Moore about skepticsm.

\section{Keywords:}

Certainty, Wittgenstein, skepticism, gramatical propositions, empirical propositions

Aunque el presente seminario trata sobre Wittgenstein empezaré hablando de George Edward Moore. Este filósofo británico en su ensayo titulado $A$ defence of common sense se pregunta acerca de si sus manos son reales, y contesta agitando las mismas delante de su cara, como si el moverlas de esta manera constituyese una prueba contundente de su realidad.

Comenzaré hablando de él porque a lo largo del texto que ocupa este seminario - Über Gewissheit-, Wittgenstein dialoga en varias ocasiones con Moore y utiliza la crítica de éste al escepticismo para esclarecer su propia visión sobre el tema.

\footnotetext{
*Universidad de Málaga. srachinarro@gmail.com
} 
Pero antes es importante aclarar lo que significa el término escepticismo en este contexto. Tanto Moore como Wittgenstein han centrado sus críticas en el escepticismo sobre un mundo material según el cual nuestras percepciones sensoriales no representan o corresponden a ningún objeto real, ya que no hay razón alguna para suponer que tal realidad material exista.

Los escépticos y los no escépticos comparten la idea de que los seres humanos percibimos sensaciones (vemos ciertos colores y formas, oímos ciertos sonidos, etc.). La diferencia estriba en que mientras los no escépticos sostienen que estas sensaciones nos informan sobre el mundo real, ya que representan o corresponden a la realidad material, los escépticos lo niegan. Un escéptico sostendría que no hay ninguna razón para suponer que nuestras sensaciones nos informen sobre nada real, y por lo tanto no existe ninguna razón para creer que el mundo material exista.

Para introducir la duda acerca de la realidad del mundo material el escéptico nos aísla del contexto de lo cotidiano. Abre una brecha desligando el concepto de sensación del de mundo material, y una vez abierta ésta es muy difícil de cerrar.

Encontramos un ejemplo de esto en las Meditaciones de Descartes. Al introducir la noción de Genio Maligno el contexto de lo cotidiano se quiebra. Cuando simplemente hacemos cola en el supermercado o corremos detrás del autobús, es muy difícil que se nos ocurra pensar que nuestras sensaciones puedan no corresponder a objetos reales. Sin embargo, cuando Descartes menciona al Genio, el contexto de lo cotidiano se quiebra, el concepto de sensación se desliga del de realidad, y por esa grieta empiezan a colarse las dudas del escéptico.

Un ejemplo más actual del escepticismo es aquel que maneja la noción de Datos de los sentidos (DS) para abrir una brecha entre sensaciones y objetos materiales. Según esta teoría un escéptico señalaría que cuando estamos hablando, por ejemplo, de estar "viendo un pájaro", lo que deberíamos decir, para ser precisos, es que estamos "viendo ciertos datos de los sentidos". En el sentido estricto, lo que estamos viendo no es el pájaro en si, sino sólo aquellos datos sensoriales que supuestamente corresponden al pájaro real. Según esta teoría los Datos de los sentidos son objetos dependientes de la mente de los que tenemos una certeza absoluta y que se supone corresponden a objetos del mundo material de cuya existencia o propiedades muchas veces no tenemos certeza. Es difícil poder demostrar que estos DS representen o 
correspondan efectivamente a ningún objeto real. Demostrar algo así supondría conseguir pruebas que relacionasen los DS con la realidad material. Pero, para conseguir tales pruebas, nos haría falta poder ir "más allá" de los DS, y comprobar así que en efecto existe una relación entre éstos y los objetos reales. Como no podemos ir más allá de los datos que nos proporcionan nuestros sentidos, no podemos demostrar que exista tal relación, y por lo tanto tampoco nos es posible demostrar que la realidad material exista.

Como dije al comienzo, Moore se pregunta si sus manos son reales, y contesta a esta pregunta agitando las manos, como si el moverlas constituyese una prueba contundente de su realidad. Así mismo, Moore presenta en un ensayo una serie de cosas que él afirma saber, como por ejemplo que existe un cuerpo humano vivo que es su cuerpo. Aunque nos pueda parecer insuficiente que él diga que sabe esas cosas para que creamos que de hecho existen, Moore está señalando aquí algo importante. Al agitar las manos delante de su cara e insistir en que sabe toda una serie de cosas, Moore nos está arrastrando de vuelta al contexto de lo cotidiano, nos pide que consideremos el problema de la realidad desde una perspectiva más familiar. Moore está diciendo al escéptico que si se decide a aislar el contexto de lo cotidiano para introducir una duda, le corresponde a él -al escéptico- justificar ese aislamiento, ese cambio de contexto, y no a nosotros defender nuestras creencias habituales.

Moore da a entender que sus desacuerdos con el escéptico deben ser resueltos utilizando métodos propiamente empíricos. Por eso cuando surge el dilema de qué contexto es el legítimo, el cotidiano o el que defiende el escéptico, podemos tender a pensar que este desacuerdo debe ser resuelto de una manera empírica. Pero los métodos de resolución del empirismo no son de ninguna utilidad aquí. Un desacuerdo de tipo empírico solo se resuelve aportando más información de tipo empírico, es decir aportando más datos obtenidos a través de los sentidos.

Hace algunos días un pájaro negro visitó el balcón de mi casa, mientras yo vi un cuervo mi amiga discrepó afirmando que era un mirlo, la luminosidad y nuestra incipiente presbicia nos animó a acercarnos para mirarlo más de cerca. Nuestro desacuerdo fue típicamente empírico, y la manera de resolverlo pasaba por reunir más información, mas evidencia sensorial. Resolvimos este problema acercándonos a lo que resultó ser, finalmente, un mirlo.

El problema de Moore es que la cuestión de qué contexto tiene más legitimidad no puede ser resuelta de esta manera, aportando 
más datos sensoriales. Si se tratase de una disputa de tipo empírico, como afirma Moore, podría ser resuelta reuniendo más información sensorial. Pero para conseguir el tipo de información adecuada necesitaríamos poder ir más allá de las sensaciones. Tendríamos que poder comprobar, desde una perspectiva externa, si el escéptico tiene razón en afirmar que nuestras sensaciones no corresponden a ningún objeto en el mundo material.

Sólo así conseguiríamos decidir cuál de los dos contextos es legítimo. Pero no se puede alcanzar tal perspectiva. Por lo tanto, es imposible decidir cual de los dos contextos debe de considerarse como válido hasta que se demuestre lo contrario. La conclusión sería que o Moore acepta que las creencias cotidianas no tienen más fundamento que las del escéptico, y por lo tanto que la postura escéptica es igual de válida que la suya, o acepta que la disputa entre escépticos y antiescépticos no es empírica por naturaleza, es decir que no puede ni debe ser resuelta mediante los métodos de resolución propios del empirismo; no puede ser resuelta aportando más información y pruebas sensoriales o hablando de saber. Llegados a este punto es donde Wittgenstein entra a dialogar con Moore.

(SC 481) Cuando oímos que Moore dice "Sé que eso es un árbol", comprendemos, de repente, a los que afirman que tal cosa no está decidida en modo alguno. metafísico ${ }^{l}$.

(SC 482) Es como si el "Sé..." no tolerara ningún énfasis

Wittgenstein considera que tanto los argumentos de Moore como los del escéptico no son suficientes ya que ambos tratan ciertas proposiciones de manera equivocada, esto es, como si fuesen empíricas y epistémicas por naturaleza. Esta equivocación surge, según Wittgenstein, porque Moore y el escéptico no se dan cuenta de que estas proposiciones constituyen un marco de referencia para todos nuestros juegos de lenguaje. Estas proposiciones, a las que Wittgenstein se refiere como proposiciones gramaticales (PG), expresan aquellas creencias que damos por sentadas cuando nos encontramos en el contexto de lo cotidiano, y que son aquellas de las que el escéptico pretende hacernos dudar. Las constituyen el conjunto de opiniones expresadas y no expresadas que forman el marco de fondo totalmente dado por sentado al describir e

\footnotetext{
${ }^{1}$ Wittgenstein, L. Sobre la certeza Barcelona: Gedisa, 1997.
} 
indagar sobre el mundo, y al confirmar o desmentir creencias. Una PG seria, por ejemplo, "Hay objetos físicos" o "mis manos son reales". Las proposiciones gramaticales no forman parte del juego sino que están situadas al comienzo de éste, son reglas de juego. Carecen de sentido porque el sentido se da en el uso del lenguaje, es decir, dentro del juego, en lo que se dice. No podemos dar razones de la PG porque son el fundamento de toda razón. Ellas constituyen la condición de posibilidad de que podamos dar razones.

Los desacuerdos que surgen entre escépticos y antiescépticos no se pueden resolver, por lo tanto, utilizando los métodos de resolución típicos del empirismo y de la epistemología. Sus desacuerdos se resuelven, al contrario, comprendiendo que las proposiciones que manejan son muy distintas de las empíricas, que la certidumbre que nos inspiran no tiene nada que ver con la que nos puede proporcionar una proposición de tipo epistémico y empírico.

En Sobre la Certeza. Wittgenstein da cuatro razones principales para esto:

En primer lugar, Wittgenstein señala que cuando un sujeto $\mathrm{A}$ le dice «yo sé que $\mathrm{x}$ » a un sujeto $\mathrm{B}$, uno supone automáticamente que $\mathrm{A}$ posee una información que B no tenía previamente. Suponemos esto porque la gramática de las proposiciones de tipo empírico así lo requiere.

Una de las normas de este juego de lenguaje es que, cuando alguien dice «yo sé que x». existe el supuesto de base de que lo dice porque posee ciertos datos suplementarios que muestran que $\mathrm{x}$. La expresión "yo sé que $\mathrm{x}$ " contiene implícitamente un deseo y una capacidad de informar, de aportar datos nuevos sobre x. Las PG, sin embargo, no se ciñen a este modelo. Cuando Moore le dice al escéptico que él "sabe" que su mano es real, no lo dice porque posea un dato que le faltaba al escéptico. Tanto es así que Wittgenstein escribe: (SC 100) Las verdades que Moore afirma saber son tales que, dicho sea de paso, si él las sabe, todos las sabemos. ${ }^{2}$

Cuando alguien afirma que "sabe" una PG, no existe el supuesto de base de que esta persona posee y puede proporcionar una información que no teníamos previamente.

La segunda razón por la cual las PG no se ciñen a las normas del juego lingüístico de lo empírico es la siguiente: este juego dicta que sólo es legitimo el decir que "yo sé que $\mathrm{x}$ " si es posible apoyar o

${ }^{2}$ Ibídem 
justificar esta afirmación. "Sé..." está vinculado a la posibilidad de demostrar la verdad (SC 243). Las PG, sin embargo, no pueden ser apoyadas o justificadas ya que, para hacerlo, tendríamos que valernos de algo que fuese más seguro que ellas. Y no existe nada que sea más seguro que las PG, porque son precisamente ellas las que forman el límite de lo que es seguro. Wittgenstein escribe: Pero si lo que cree es de tal tipo que las razones que puede dar no son más seguras que su aserción, no puede decir que sabe lo que cree (SC 243). ${ }^{3}$ Por lo tanto, las PG se diferencian de las proposiciones que sí son empíricas en que no pueden ser apoyadas y justificadas.

En Sobre la Certeza Wittgenstein introduce el concepto de creencia. Las creencias son certezas prácticas que funcionan como reglas que rigen nuestro actuar. Este sistema de creencias compone una especie de mitología que Wittgenstein denomina "imagen del mundo". Él dice que no tenemos esa imagen del mundo porque estemos convencidos de su corrección, sino que esa imagen del mundo es el trasfondo sobre el cual distinguimos entre lo verdadero y lo falso.

En tercer lugar, las proposiciones de tipo empírico consisten en hipótesis que pueden ser, además de apoyadas, puestas en duda. En el caso de las PG, al contrario, carecemos de la distancia necesaria para poder dudar de nada, ya que el dudar de una PG equivale a minar todo nuestro esquema mental. Una duda en este punto parecería arrastrar todo consigo y reducirlo a un caos (SC 613). ${ }^{4}$ Esto no ocurre en el juego de lenguaje de lo empírico; no hay nada trágico en dudar de que "aquel pájaro sea un cuervo o un mirlo". Esta duda puede ser resuelta fácilmente examinándolo más de cerca. Es más, aunque por cualquier razón no pudiese ser resuelta, esto no afectaría drásticamente a nuestra visión del mundo. En contraste, cuando empezamos a dudar de la realidad, del mundo que nos rodea, nuestras creencias pueden dejar de tener sentido.

Por último, en el juego lingüístico de lo empírico y lo epistémico se hace uso abundante del concepto de error. Un error es una falsa creencia que puede ser rectificada y por lo tanto ajustada de nuevo al conjunto de creencias que sabemos son correctas. Para que el concepto de error resulte inteligible, debe haber un fondo fijo de creencias que podamos dar por sentado. Si todas nuestras creencias fuesen errores, el concepto de error perdería totalmente sentido. Para que un hombre se

\footnotetext{
${ }^{3}$ Ibídem

${ }^{4}$ Ibídem
} 
equivoque, ha de juzgar ya de acuerdo con la humanidad (SC 156). ${ }^{5} \mathrm{Y}$, como las PG constituyen precisamente el conjunto fijo de creencias que damos absolutamente por sentado, no tiene sentido el hablar de error en lo que se refiere a ellas. Son las PG las que hacen posible que el concepto de error sea inteligible, si dejásemos de darlas por supuesto la noción de error en si dejaría de tener sentido.

Ahora bien, me gustaría considerar tal seguridad no como algo parecido a la precipitación o a la superficialidad, sino como (una) forma de vida. (SC 358). ${ }^{6}$

Wittgenstein, con su noción de juegos del lenguaje recalca que el lenguaje es una actividad humana que se encuentra inmersa en todo un sistema de prácticas, tanto lingüísticas como no lingüísticas. Es por ello que Wittgenstein sostiene que imaginar un lenguaje significa imaginar una forma de vida.

¿no está (ya) presupuesta esta seguridad en el juego de lenguaje? Es decir, en el hecho de que quien no reconoce los objetos con seguridad no juega, o juega mal (SC 446). ${ }^{7}$

Las creencias más básicas de nuestra imagen del mundo carecen de fundamento ya que no podemos dar razones de ellas. Si no diésemos las PG totalmente por sentado nos resultaría imposible el hablar de saber y probar o demostrar nada. Para que los juegos lingüísticos que se valen de las nociones de saber y demostrar sean inteligibles, hace falta que demos por supuestas las creencias expresadas por las PG. Del mismo modo, si es imposible el dudar de y cometer errores en lo que se refiere a las PG, esto no se debe a que éstas hayan sido demostradas más allá de toda duda y error. No puede haber duda o error en lo que se refiere a las PG porque si dudásemos o errásemos sobre ellas, los propios conceptos de error y de duda dejarían de tener sentido.

Eva Parra Iñesta es estudiante de filosofía de la Universidad de Málaga.

$$
\begin{aligned}
& { }^{5} \text { Ibídem } \\
& { }^{6} \text { Ibídem } \\
& { }_{7}^{7} \text { Ibídem }
\end{aligned}
$$


Este trabajo, sobre la certidumbre, reproduce la ponencia de Eva Parra del 6 de abril de 2010, en el centro cultural Vicente Aleixandre, Alhaurín de la Torre (Málaga), y que supuso el acto final con el que se cerró el ciclo de seminarios en torno a la verdad organizados por Claridades. Revista de filosofía en colaboración con el área de filosofía del departamento de filosofía de la Universidad de Málaga. 